\title{
SEGURANÇA NO TRÂNSITO: DIREITO E RESPONSABILIDADE COLETIVA
}

\author{
Tiago Dantas Sebastião da Silva ${ }^{1}$
}

RESUMO: Em busca por soluções inovadoras, o respectivo artigo busca analisar e estabelecer o vínculo real entre trânsito e segurança pública, entre os três elementos que compõem o sistema de tráfego (veículo, via e usuário), na perspectiva dos dias atuais; é de vital importância um esforço coletivo dos agentes ativos e passivos na formulação de soluções, alternativas e modelos na promoção das melhores práticas segurança urbana ativa, com a elaboração e aplicação de politicas públicas, respaldadas nos critérios e dispositivos legais das esferas nacionais e municipais. O Sistema Nacional de Trânsito, formado por um conjunto de órgãos e entidades, como instituição que coordena as devidas ações, necessitam atuar com maior efetividade, quanto a segurança para o trânsito, principalmente com ferramentas estratégicas no desenvolvimento de espaços urbanos inteligentes, ações planejadas que podem potencializar a maneira de conhecer e atender sobre a necessidade desse assunto, com a finalidade de implementar novas e contínuas soluções sociais. A aplicabilidade e viabilidade sobre segurança no trânsito, está regulamentada em normativas e diretrizes legais, onde todos os envolvidos assume papel principal na conscientização desse conhecimento, provendo um comportamento seguro, com habilidades e atitudes para evitar acidentes, comtemplando a preservação da vida e exercício da cidadania, o objetivo mais desafiador nessa premissa, é gerar uma cultura de segurança no trânsito, onde o ser humano é o agente primário de possível transformação do espaço social no deslocamento, em um local de respeito, e certamente isso se deve começar pela educação. Assim, a presente pesquisa evidencia a importância da segurança no trânsito, como estratégia de transformação social, o tema pode ser aprofundado no futuro nesta linha de pesquisa pelas comunidades científicas e acadêmicas.

Palavras-chave: Segurança. Direitos Fundamentais. Trânsito.

ABSTRACT: In search of innovative solutions, the respective article seeks to analyze and establish the real link between traffic and public safety, between the three elements that make up the traffic system (vehicle, lane and user), from the perspective of today; a collective effort by active and passive agents in the formulation of solutions, alternatives and models to promote the best practices in active urban security is vitally important, with

${ }^{\mathrm{I}}$ Tutor EaD no Grupo Ser Educacional / Bacharel em Administração de Empresas pela Faculdade de Ciências Humanas e Sociais de Igarassu (FACIG) / Tecnólogo em Gestão de Sistemas de Informação pela Universidade Paulista (UNIP) / Pós-graduação: MBA em Gestão Estratégica de Pessoas pela Faculdade de Ciências Humanas Esuda / Pós-graduando em Metodologia do Ensino à Distância pela Universidade da Amazônia (UNAMA) / E-mail: tiagodantas3o@hotmail.com 
the elaboration and application of public policies, supported by the criteria and legal provisions of the national and municipal spheres. The National Traffic System, formed by a set of bodies and entities, as an institution that coordinates the appropriate actions, needs to act with greater effectiveness in terms of traffic safety, especially with strategic tools in the development of intelligent urban spaces, planned actions that they can enhance the way to learn about and respond to the need for this matter, with the aim of implementing new and continuous social solutions. The applicability and feasibility of traffic safety is regulated in legal regulations and guidelines, where everyone involved assumes a main role in raising awareness of this knowledge, providing safe behavior, with skills and attitudes to avoid accidents, contemplating the preservation of life and the exercise of citizenship, the most challenging objective in this premise, is to generate a culture of traffic safety, where the human being is the primary agent of possible transformation of the social space in displacement, in a place of respect, and this should certainly start with education. Thus, this research highlights the importance of traffic safety, as a strategy for social transformation; the scientific and academic communities can deepen the theme in the future in this line of research.

Keywords: Security. Fundamental Rights. Traffic.

\section{INTRODUÇÃO}

O presente artigo está estruturado em três partes: a primeira apresenta um breve histórico e conceitos sobre Segurança no Transito, a segunda evidencia sobre os Direitos

Fundamentais, e por fim, o terceiro, destaca o Comportamento e Responsabilidade Coletiva de todos no que diz respeito à Segurança Trânsito, colocando em destaque a correlação existente entre todos os pontos abordados, sua importância e seus efeitos na sociedade; mostrando os aspectos políticos e legais, ou seja, os princípios estabelecidos na lei e as diretrizes gerais de suma importância ao desenvolvimento de políticas responsivas, com destaque as autarquias governamentais, instituições de ensino, empresas privadas e sociedade, responsável por estabelecer e fixar praticas sobre segurança no transito, discorrer sobre práticas que orientam o processo formativo dos cidadãos dentro desse contexto, a relevância de ferramentas estratégicas, ações e projetos atrelados a realidade social do cotidiano das pessoas. O principal desafio é superar a cultura de um trânsito centrada no carro e aplicar modelos mais estratégicos e realistas, orientados por uma preocupação coletiva, que busca elencar os principais pontos que devem nortear uma formação efetiva e 
progressiva que tem papel fundamental para o desenvolvimento das cidades e da qualidade de vida da população, com isso, a mesma precisa ser pensada numa perspectiva mais ampla.

Esta pesquisa caracteriza-se em uma revisão da literatura, contempla um processo de investigação que envolve localizar, analisar, sintetizar e interpretar os dados de diversas fontes de conhecimento relacionados ao tema da pesquisa (revistas científicas, livros, resumos, artigos, etc.), valida-se dos discursos de diversos pesquisadores e estudiosos, reconhecendo a contribuição dos mesmos, a fim de evidenciar a relevância da pesquisa realizada.

A metodologia utilizada para realização desta pesquisa foi a revisão de literatura, narrativa e tradicional, permitindo uma temática mais aberta em seu desenvolvimento e com menos rigidez. A seleção dos artigos é arbitrária, porém com responsabilidade e centrada no objetivo da temática proposta, valendo-se de informações sujeitas ao viés de seleção do seu autor, com significativa interferência da percepção subjetiva, no entanto, direcionando para resultados objetivos, onde o escopo central tem interesse de evidenciar sobre Segurança no Trânsito em seus aspectos representativos e relevantes na sociedade para desenvolvimento digno e perene de todos os envolvidos ativamente ou passivamente.

Possui uma abordagem Interdisciplinar, por agrupar e agregar vário outros saberes, contudo, dentro de uma correlação que busca esclarecer a temática abordada, recorrendo a informações de vários conhecimentos para análise de uma determinada premissa, assim sendo, preocupa-se em interligar os saberes entre si para trazer lucides e sensibilizar sobre a importância do assunto. Nesse contexto, cada conhecimento/ciência contribui com informações próprias do seu campo de conhecimento, considerando que existe uma integração entre elas. É um tipo de saber específico, que possui um objeto determinado e reconhecido, com conhecimentos e saberes relativos a esse objeto de estudo e métodos próprios possíveis de correlacionar dentro de uma lógica inteligível, dentro de uma realidade mais holística e integrada do conhecimento disponível, nas várias conexões entre os elementos, combinando estes para compor uma alternativa ou hipótese mais favorável e inovadora. 
Por fim, corresponde a um compendio de citações que analisa a importância da Segurança no Trânsito, como foco nos direitos e deveres dentro da responsabilidade coletiva, com o objetivo de compreender os desafios enfrentados dessa temática, por estar constantemente no cotidiano das pessoas, tornando-se um fator social, partindo do pressuposto de que os envolvidos vivem em um ambiente dinâmico e necessita de uma avaliação constante para uma boa gestão de suas atividades, principalmente no que trata a segurança da vida humana.

\section{DESENVOLVIMENTO}

\section{I.I Segurança no Trânsito: Breve Histórico e Conceito}

Atualmente é inegável a conexão entre Trânsito e Segurança Pública são assuntos que tem uma correção abrangente e devem ser analisados conjuntamente, contudo verificase a importância de conceituá-los distintamente. Assim sendo, inicia-se com algumas definições de trânsito por alguns autores e estudiosos do tema e pelo próprio Código de Trânsito Brasileiro - CTB.

Segurança no Trânsito é uma preocupação antiga, historicamente, "os primeiros

relatos de restrições ao tráfego de veículos datam do Império Romano, quando Júlio César proibiu o tráfego de veículos durante o dia com o objetivo de diminuir os acidentes com bigas" (BÔAS E SILVA, 2015 apud ROZESTRATEN, 1988). Ainda no período Romano, o número de carroças que podiam circular na cidade foi limitado por outros imperadores por entender e observar que o aumento dessas carroças em circulação sem um controle efetivo, proporcionava o aumento de problemas de mobilidade e circulação dos diferentes elementos envolvidos e, consequentemente, as restrições inerentes.

Ainda segundo Bôas e Silva (2015), citando Rozestraten (1988):

Segurança e Trânsito sempre foram preocupações que evoluíram lado a lado e que vem desde século XVII na Europa. Inicialmente a preocupação dos estudiosos da questão limitava-se à mobilidade das pessoas e dos veículos e, mais tarde, também a via, não apenas enquanto lugar de acesso dos demais elementos, mas pela dinamicidade que os envolviam, passando gradativamente a exigir normas de circulação, com o fim maior de integrar e proteger os diferentes elementos aí envolvidos, se tratando, desde então, de segurança e da segurança de todos no 
espaço público."

A preocupação e consciência sobre o trânsito torna-se mais relevante no século XVII e XVIII, normas que delimitavam estacionamentos e circulação de veículos em mão única e dupla já existiam na Europa. A Revolução Industrial, com a introdução da máquina, a criação dos veículos rápidos e pesados, trouxeram aumento dos acidentes progressivamente, com isso, no século $\mathrm{XX}$, imperativamente foram criadas medidas que regulamentavam o fluxo e a interação entre os veículos, o ambiente físico e principalmente as pessoas, organizando o tráfego como um sistema convencional, dando origem aos Códigos de Trânsito, no Brasil o Código de Trânsito Brasileiro (CTB).

Conforme Boas e Silva (2015), citando Rozestraten (1988), segurança e trânsito sempre fora a preocupação dos estudiosos, estudando a:

Mobilidade das pessoas e dos veículos e, mais tarde, também a via, não apenas enquanto lugar de acesso dos demais elementos, mas pela dinamicidade que os envolviam, passando gradativamente a exigir normas de circulação, com o fim maior de integrar e proteger os diferentes elementos aí envolvidos, se tratando, desde então, de segurança e da segurança de todos no espaço público."

Diretamente relacionado a afirmação acima, destaca-se o elemento humano, o condutor, componente de maior importância e complexidade, devido sua capacidade de desorganizar todo o sistema, onde o comportamento do mesmo, com relação as Normas Gerais de Circulação e Conduta merecem atenção especial com uso do bom senso ou da boa educação, entretanto, bom senso apenas não é suficiente para o restante das normas, contudo, a maior parte delas exige do usuário o conhecimento da legislação específica e a disposição de se pautar por ela.

Para Bottesini e Nodari (20II) essa importância de aspectos relacionados ao comportamento do condutor/motorista caracteriza-se:

do fato de que este é capaz de influenciar as demandas do sistema através de escolhas comportamentais, idealmente tornando-as compatíveis com sua capacidade. Cabe destacar a diferença existente entre comportamento e desempenho do motorista. Enquanto o desempenho está associado a tudo o que o motorista está capacitado a fazer, o seu comportamento diz respeito ao que ele escolhe fazer."

Entende-se por segurança que o condutor do veículo deve de acordo com as regras 
vigentes e as boas condutas no trânsito, exercer e conscientizar-se da cidadania em benefício do bem comum, quanto à abordagem dos inúmeros aspectos que compõem o trânsito. A compreensão efetiva e consciente das normas de circulação, as infrações e penalidades previstas no CTB (Código de Trânsito Brasileiro), bem como a direção defensiva.

\subsection{Direitos Fundamentais}

A Constituição Brasileira de 1988 apresenta um significado singular e especial aos direitos individuais, evidenciado logo no início do texto constitucional, denotando a intenção do constituinte. Esses direitos constituem patrimônio comum da humanidade, construído ao longo dos anos, em complemento a constituição, surge as práticas e ações do Direito Civil no Trânsito, com o objetivo de fomentar a promoção de comportamentos seguros e a proteção da qualidade de vida dos condutores e não condutores. (AMANDA, 2019)

Amanda (2019), destaca que a expressão "direitos fundamentais”, não é a única utilizada para denotar o rol de direitos e garantias individuais do homem, podemos observar seus sinônimos, a saber: "direitos do homem ou direitos humanos, direitos individuais, liberdades públicas ou ainda direitos políticos subjetivos".

Assim sendo, Amada (2019) entende e defende que:

O exercício da democracia plena deva se pautar por um novo referencial, condizente com o Estado de Direito hoje existente no Brasil, ou seja, uma nova visão de segurança, agora como espaço de participação comunitária, pública ainda, mas não limitada ao Estado, também afeta às demais áreas do governo - também social e não apenas criminal -, como uma abordagem que concilie outras disciplinas. Um conceito de segurança pública entendida como compatível ao texto ora apresentado deve levar em consideração princípios da Dignidade Humana, da Interdisciplinaridade, da Imparcialidade, da participação Comunitária, da Legalidade, da Moralidade, da Transparência, do Pluralismo, da Responsabilidade, entre outros."

É direito de todo o cidadão a segurança no trânsito, os órgãos e entidades que compõem o Sistema Nacional de Trânsito (SNT) devem assegurar, a todo cidadão, condições seguras para transitarem nas vias terrestres, conforme subscrito no parágrafo $2^{\circ}$ e artigo Io do Código de Trânsito Brasileiro (CTB).

Art. I으 (...) 
$\S 2^{\mathrm{o}} \mathrm{O}$ trânsito, em condições seguras, é um direito de todos e dever dos órgãos e entidades componentes do Sistema Nacional de Trânsito, a estes cabendo, no âmbito das respectivas competências, adotar as medidas destinadas a assegurar esse direito. (CTB)

O direito constitucional de um trânsito seguro decorre do próprio direito fundamental genérico da segurança, pertencentes ao título II (Dos direitos e garantias fundamentais) da nossa Constituição Federal, nos artigos $5^{\circ}$ e $6^{\circ}$, que assim expressam:

Art. 5‥ Todos são iguais perante a lei, sem distinção de qualquer natureza, garantindo-se aos brasileiros e aos estrangeiros residentes no país a inviolabilidade do direito à vida, à liberdade, igualdade, segurança e propriedade, nos termos seguintes: [...]

Art. 6ㅇ. São direitos sociais a educação, a saúde, o trabalho, a moradia, o lazer, a segurança, a previdência social, a proteção à maternidade e à infância, a assistência aos desamparados, na forma desta Constituição.

Nesse sentido, o direito ao trânsito seguro encontra-se no rol de direitos fundamentais, destacando que não se trata apenas de segurança, mas de planejamento e organização suficientes para defender a vida e incolumidade física, direito à segurança no trânsito é fundamental também pelo fato de decorrer de outros direitos fundamentais, como o direito à vida. Aponte-se, ainda, que o art. 144 da CF atribui ao Estado o dever de garantir a segurança pública, evidentemente, como forma de efetivação dos direitos prescritos no art. $5^{\circ}$.

Porém ao falarmos de "Direitos Fundamentais" devemos ter em mente também os Deveres Fundamentais", Rabelo (202I) enfatiza quais os direitos e deveres do cidadão no trânsito segundo o Código de Trânsito Brasileiro (CTB):

É dever do cidadão no Trânsito: "Transitar sem oferecer perigo ou obstáculo a si mesmo, a terceiros e ao meio ambiente".

É direto do cidadão no Trânsito: "Usufruir de vias seguras, corretamente sinalizadas, ser educado para dirigir com perfeição, opinar e sugerir alterações no código, bem como solicitar alterações, fiscalização e segurança”.

Direitos na condução do veículo: Ter vias seguras para transitar; Ter orientação adequada com propagandas e companhas sobre a legislação de trânsito e direção defensiva; Receber ajuda dos órgãos competentes, caso necessário, assim como os agentes de fiscalização; Ter um atendimento digno e respeitoso em 
qualquer repartição que atuem na administração do trânsito em qualquer parte do país; Ter acesso a assistência médica quando necessário nos casos de acidentes de trânsito.

Deveres do Motorista: Usar o cinto de segurança e os demais equipamentos obrigatórios; Conhecer o automóvel que está dirigindo; Manter o automóvel sempre em boas condições de funcionamento; Prever situações inesperadas, ficar atento e ser capaz de evitar acidentes; Ser capaz de tomar decisões corretas com rapidez nas situações de perigo e executá-las; Nunca aceite desafios e provocações de motoristas irresponsáveis; Não dirigir cansado ou com sono, sob o efeito do álcool, drogas, remédios ou qualquer substância tóxica; Não confie apenas na sua habilidade; Procure ver tudo que está acontecendo à sua volta e certifique-se de que todos estão vendo o seu veículo e a sinalização que estiver usando.

Direitos do Pedestre: É assegurada ao pedestre a utilização dos passeios ou passagens apropriadas das vias urbanas e dos acostamentos das vias rurais para circulação; Nas áreas urbanas, quando não houver passeios ou quando não for possível a utilização destes, a circulação de pedestres, na pista de rolamento, será feita com prioridade sobre os veículos, pelas bordas da pista, em fila única, em sentido contrário ao deslocamento de veículos, exceto em locais proibidos pela sinalização e nas situações em que a segurança ficar comprometida; Os pedestres que estiverem atravessando a via sobre as faixas delimitadas para esse fim terão prioridade de passagem, exceto nos locais com sinalização semafórica, onde deverão ser respeitadas as disposições deste código; Nos locais em que houver sinalização semafórica de controle de passagem será dada preferência aos pedestres que não tenham concluído a travessia, mesmo em caso de mudança do semáforo liberando a passagem dos veículos;

Para que os direitos e deveres acima descritos tem sua eficácia, os objetivos básicos

fixados no artigo 6o do CTB, tenham sua efetividade.

Art. 6o São objetivos básicos do Sistema Nacional de Trânsito:

I - estabelecer diretrizes da Política Nacional de Trânsito, com vistas à segurança, à

fluidez, ao conforto, à defesa ambiental e à educação para o trânsito, e fiscalizar seu cumprimento;

II - fixar, mediante normas e procedimentos, a padronização de critérios técnicos, financeiros e administrativos para a execução das atividades de trânsito;

III - estabelecer a sistemática de fluxos permanentes de informações entre os seus diversos órgãos e entidades, a fim de facilitar o processo decisório e a integração do Sistema (BRASIL, I997).

Aliando aos pressupostos normativos, segundo (RODRIGUES, 2016) ainda é importante dentro desse contexto, "concretizar as relações sociais, as interações entre os mais diversos componentes do trânsito, bem como o comportamento de seus usuários de 
modo a evitar que ocorram principalmente os acidentes de trânsito, que são responsáveis por diversas fatalidades". Vale evidenciar que as relações sociais na interação dos diversos componentes mostram de forma pratica o exercício da cidadania, mantendo a segurança e a organização com a conscientização do cumprimento das normas existentes.

Exercer a cidadania no trânsito não é pensar somente na própria segurança ou na segurança do outro, mas sim em um sistema seguro como um todo. E é nesse ponto que se pode afirmar que um indivíduo só será capaz de cooperar para o bom funcionamento desse sistema, que é o trânsito, se, além de motorista ou pedestre, ele for também um cidadão. Onde há cidadania, há cooperação mútua para a manutenção da organização e da segurança de um sistema. Um sistema que apresentar organização e segurança apresentará também o funcionamento esperado por cada uma das pessoas que o utiliza." (POLITIZE, 2017)

Diante disso o exercício da cidadania é colocado em evidencia, podemos observar na definição acima que seu entendimento é mais abrangente, cujo maior objetivo, são as pessoas, os cidadãos, priorizando a melhoria nas condições gerais de deslocamento na cidade e segurança, com ações de valorização, refletindo diretamente no desenvolvimento urbano e garantia do direito fundamental, o direito a liberdade fundamental de ir e vir; essas normativas regulam o sistema de convívio entre o pensar e agir das pessoas, que regem a sociedade e respeitam as individualidades dentro do ambiente social com segurança, observando os critérios éticos e morais, nos aspectos democráticos que regem nosso país, buscando nossos DIREITOS, equiparados ao nível de importância dos nossos DEVERES.

\section{I.3 Responsabilidade Coletiva: Comportamento Seguro de Todos}

Para Tiemi (2019), segurança no trânsito é um "processo exige enorme esforço das áreas envolvidas, ou seja, toda a sociedade. Então governo, empresas privadas, meio acadêmico e iniciativas da sociedade em geral são protagonistas nesta ação, já que visam o fortalecimento de uma cultura e valores de todas as esferas."

Setor Público: o governo estará presente, uma vez que é dele a responsabilidade de garantir o direito de ir e vir em segurança dos cidadãos. Este setor tem um importante papel, pois suas ações podem alcançar todo o país propondo iniciativas de caráter permanente, tanto de fiscalização quanto de prevenção.

Área Acadêmica: segurança neste cenário, aborda um tema multidisciplinar em que áreas de Exatas, Humanas e Biológicas podem contribuir para o alcance de um trânsito mais seguro. As ações proporcionaram experiências educativas, 
culturais e científicas, que articularam ensino, pesquisa e extensão, estimulando a cultura de segurança do trânsito

Setor Privado: uma vez que existe enorme quantidade de motoristas que atuam profissionalmente em empresas de diversos segmentos, estes passando muito tempo no trânsito e consequentemente se expondo mais aos riscos, nos aspectos segurança do trabalho; já existem várias empresas que possuem excelentes programas de segurança no trânsito, disseminando os conhecimentos para seus motoristas, demais colaboradores, familiares, clientes e fornecedores, contribuindo muito para o fortalecimento de uma cultura de segurança.

Sociedade: a sociedade também desperte para a problemática do trânsito e se engaje na busca por soluções para mudanças de comportamento e iniciativas de conscientização. Conduzindo profissionalmente ou não, o trânsito é composto por cidadãos e todos possuem um papel fundamental na disseminação e implantação da cultura de segurança no trânsito.

O comportamento dos cidadãos assume papel decisivo no que diz respeito à segurança, a identificação das medidas de segurança de trânsito que apresentam potencial de relevância para um comportamento seguro, ajudam na definição de programas de segurança com bom nível de eficiência e confiabilidade, possíveis de moldar o espaço coletivo, influenciando hábitos que podem transformar lugares e mudar a vida das pessoas, promovendo a cidadania. Segundo Bottesini e Nodari (2011) apud Shinar (2007), sobre a teoria do comportamento planejado, de Icek Ajzen (2002), o comportamento humano é influenciado por três tipos de considerações ou crenças:

I. Crenças Comportamentais: são aquelas relativas aos possíveis resultados do comportamento e sua avaliação. Essas crenças provocam atitudes (favoráveis ou desfavoráveis) em relação ao comportamento.

2. Crenças Normativas: referem-se às expectativas de terceiros e à motivação para adequar-se a essas expectativas. Resultam na norma subjetiva (ou "pressão social percebida").

3. Crenças de Controle: são aquelas relativas à presença de fatores que possam facilitar ou impedir a execução do comportamento, e ao poder percebido desses fatores, gerando assim, o controle comportamental percebido.

$\mathrm{Na}$ perspectiva de tornar o comportamento no trânsito o mais previsível e seguro 
possível, a legislação de trânsito, é uma importante medida de segurança, que utilizada as normas de fiscalização e as sanções legais, aliados a medidas de educação e informação ao público, com campanhas de conscientização, para reduzir acidentes, promover um comportamento seguro no trânsito, esclarecer as restrições impostas, "o reconhecimento de que escolhas individuais refletem no coletivo, na defesa e na qualidade da vida e na mudança de estilos de vida”.

O conhecimento da Normas de Circulação, Infrações, Penalidades e Direção Defensiva conforme descrito abaixo, nos seus mínimos detalhes, não apenas nos cursos de formação de condutores, mas também, nas salas de aulas, como elemento de conteúdo complementar e interdisciplinar no currículo escolar, de forma planejada é instrumento de incentivo a educação e segurança, uma vez que integram o homem, meio ambiente e realidade social, influenciando no contexto em que vive todos os indivíduos.

AS NORMAS DE CIRCULAÇÃO: I. Deveres do condutor; 2. Regras gerais para a circulação de veículos; 3. Regras de ultrapassagens; 4. Regras para manobras e mudanças de direção; 5. Uso da buzina; 6. Uso de luzes e sinalização; 7. Regras de preferência e de passagem em cruzamentos e passagem de nível; 8. Estacionamento e parada; 9. Velocidade e distância entre veículos; Io. Regras relativas a veículo de transporte coletivo; II. Regras para redução da velocidade; 12. Redução de marcha, imobilizações temporárias e paradas emergenciais; 13. Abertura de porta dos veículos; I4. Regras aplicáveis aos pedestres; 15. Regras aplicáveis aos ciclistas; ı6. Regras aplicáveis à condução de animais e a veículos de tração animal; 17. Comportamento dos condutores em relação aos pedestres e ciclistas; I8. Regras aplicáveis a condutores e passageiros de motocicletas, motonetas e ciclomotores; 19. Regras aplicáveis aos condutores profissionais; 20. Uso de equipamentos obrigatórios.

INFRAÇÕES E PENALIDADES: I. Infração de trânsito; 2. Responsabilidade pela infração; 3. Autoridade e o agente de trânsito; 4. Fiscalização e policiamento de trânsito; 5. O auto de infração; 6. Penalidades; 7. Medidas administrativas; 8. Natureza da infração cometida e pontuação correspondente; 9 . O processo administrativo de recurso de infração e de imposição de penalidades; ı. Crimes de trânsito. 
DIREÇÃO DEFENSIVA: ı. O que é direção defensiva; 2. Veículos: manutenção periódica e preventiva e funcionamento; equipamentos obrigatórios; sistemas de freios, suspensão, direção, iluminação e cintos de segurança; 3. Condutores: a importância do bom estado físico e mental para dirigir; conhecimento e habilidades; habilitação; uso de equipamentos obrigatórios; fatores de risco para a ocorrência de acidentes, como evitar colisões; condições adversas; 4. Vias: limites de velocidade, vias urbanas e rodovias, curvas, aclives, declives, pontes, túneis, passagens de nível, cruzamentos, sinalização, iluminação, acostamento, obras, condições de pavimento, calçadas e passeios, condições adversas; 5. Ambiente: chuva; aquaplanagem, neblina, vento, temperatura, incêndios florestais e queimadas; 6. Respeito ao meio ambiente e convívio social no trânsito.

Nesse cenário, a segurança no trânsito, a medida em que se promove culturalmente, será uma enorme conquista social, pregada e defendida constantemente, de forma intensiva e efetiva, as premissas básicas acima descritas não ficam apenas no papel ou subjetividade, mas em uma realidade e objetividade.

\section{CONSIDERAÇÕES FINAIS}

Os desafios sobre a temática são constantes, devido à escassez da sua realidade, conclui-se que foi possível com o levantamento teórico desta pesquisa, que ao analisar importância da Segurança no Transito, leva-nos a uma reflexão do comportamento dos cidadãos no que diz respeito ao transito, pois a temática requer cada dia mais o entendimento de sua real importância para garantir maior qualidade, efetividade da sua aplicabilidade e envolvimento dos personagens direta e indiretamente relacionados, compreendendo sua natureza e identificando suas características para melhor se adequar ao ambiente nos critérios que rege na legislação especifica sobre o assunto.

Ao se direcionar a um sistema de normas, com ênfase em segurança e situações correlatas, pesquisas corroboram a inegável relação do trânsito e segurança, considerando esta de forma mais ampla, mais em acordo com o Estado de Direito vivenciado pelos brasileiros nos dias atuais, como um espaço de participação comunitária, deixando de ser considerada tão somente uma questão de polícia, voltada à criminalidade e 
circunscrita ao Estado, o assunto deve considerar também novos referenciais e princípios já determinados tais como: Dignidade Humana, Interdisciplinaridade, Imparcialidade, Participação Comunitária, Legalidade, Moralidade, Transparência, Pluralismo, Responsividade, entre outros.

Considera-se imprescindível e imperativo a promoção sobre Segurança no Transito, valendo-se de ações planejadas e coordenadas pelo órgãos responsáveis do SNT, da União, dos Estados, do Distrito Federal e dos Municípios, as autarquias; as instituições acadêmicas públicas e privadas; as empresas; e a sociedade, com mecanismos de participação social, de ensino, aprendizagem e conscientização contínua a ser compartilhada e disseminada constantemente nas respectivas áreas de atuação dos mesmos, de forma sinérgica e sistêmica, gerando e viabilizando melhorias e inovações fundamentais na atual realidade, deixando um legado de ações planejadas positivas e satisfatórias para as futuras gerações.

Ressalta-se a importância do posicionamento moral, direcionados ao desenvolvimento de atitudes e valores num processo formativo de cidadãos, ou seja, o comportamento diante das normativas explicitas e implícitas sobre o assunto, para produzir soluções criativas de superação das dificuldades, consolidando a consciência que a segurança é construída passo a passo e se consolidam pelo envolvimento de todos, buscando continuamente alternativas que permitem dar visibilidade a sua aplicabilidade referente as transformações que se pretendem realizar, sendo estas transformações racionais, objetivas, precisas e satisfatórias, bem como, claras e de fácil compreensão, de forma a integrar os objetivos de médio e longo prazo as variáveis relevantes do ambiente e as necessidades decorrentes em termos de coletividade, criando elementos culturais que se orientam por meio de interesses globais.

Quando de fato a temática Segurança no Trânsito conseguir ter sua efetividade plena no Brasil, todos os envolvidos diretamente e indiretamente irão usufruir dos benefícios consequentes, pois sua aplicabilidade bem-sucedida pode resultar em soluções oportunas, exatas, flexíveis, economicamente viável e confiável, em curto, médio e longo prazo, com a análise perene das estratégias mais satisfatórias, considerando o impacto dos 
elementos, particularidade dos resultados e a relevância destes, perpetuando e aperfeiçoando os padrões sistêmicos através das normativas na legislação vigente, os mesmos só tendem a crescer.

\section{REFERÊNCIAS}

BÔAS, Eliéte Ferreira Vilas. SILVA, Marlene Alves. Trânsito e segurança pública: impactos e consequências. Humanidades, v. 4, n. 2, jul. 2015. Disponível em: < http://www.revistahumanidades.com.br/arquivos_up/artigos/a66.pdf> Acesso em: o6 mar. 202I.

BOTTESINI, Giovani. NODARI, Christine Tessele. Influência de medidas de segurança de trânsito no comportamento dos motoristas. TRANSPORTES v.í n.I (20II) p. 77-86. Disponível em: < https://www.revistatransportes.org.br/anpet/article/view/259> Acesso em: 06 mar. 202I.

BRASIL. Lei 9.503, de 23 de setembro de 1997. Código Trânsito Brasileiro. Disponível em: <https://www2.camara.leg.br/legin/fed/lei/1997/lei-9503-23-setembro-1997-372348-

publicacaooriginal-I-pl.html> Acesso em: 06 mar. 2021.

CAMPOS, Cintia Isabel. Et Al. A importância da educação de trânsito na formação de cultura de segurança no trânsito. Anais do III Seminário de Pós-Graduação em Engenharia Urbana, 2012. Disponível em: <http://www.eventos.uem.br/index.php/simpgeu/simpgeu/paper/viewFile/945/755\#: :tex

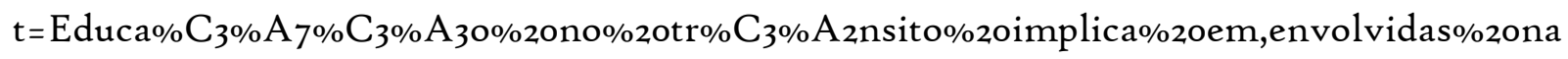
s\%20condutas\%2ode\%20tr\% $\mathrm{C}_{3} \% \mathrm{~A} 2$ nsito.> Acesso em: I4 mar. 2021.

COSTA, Amanda. Segurança no Trânsito - Direito Fundamental. Jusbrasil, 2019. Disponível em: < https://amandacostamoura.jusbrasil.com.br/artigos/599360714/segurancano-transito-direito-fundamental> Acesso em: o6 mar. 2021.

POLITIZE. Disponível em: <https://www.politize.com.br/transito-cidadania/> Acesso em: 07 mar. 2021. 
RABELO, Márcia. Direitos e Deveres do Cidadão no Transito. Clube Detran. Disponível em: <https://clubedetran.com.br/direitos-e-deveres-do-cidadao-no-transito/> Acesso em: o7 mar. 2021.

RODRIGUES, Alesandro Moreira. Educação para o trânsito: a necessidade de uma maior atuação por parte dos componentes do sistema nacional de trânsito. Disponível em: <https://riuni.unisul.br/bitstream/handle/12345/4940/ALESANDRO_RODRIGUES_Arti go_Pronto.pdf?sequence=I\&isAllowed=y> Acesso em: Acesso em: 07 mar. 2021.

TIEMI, Ana. O papel da cultura de segurança no trânsito na prevenção de acidentes. Veltec, 2019. Disponível em: 〈https://veltec.com.br/cultura-de-seguranca-no-transito/> Acesso em: I4 mar. 202I.

SILVA, T. D. S. Avaliação estratégica com base em valores organizacionais na prestação de serviços. Artigo (Pós-Graduação em Gestão Estratégica de Pessoas). Faculdade Esuda. Pernambuco, Recife, 2016. 